\title{
TRANSATLÂNTICO CINEMATOGRÁFICO: APROXIMAÇÕES E DISTANCIAMENTOS NA FORMAÇÃO DO INSTITUTO NACIONAL DE CINEMA EDUCATIVO
}

\author{
TRANSATLANTIC CINEMATOGRAPHIC: APPROXIMATIONS AND DISTANCES IN \\ THE FORMATION OF THE NATIONAL INSTITUTE OF EDUCATIONAL CINEMA
}

\author{
Rafael Fermino Beverari \\ Doutorando em Ciências Sociais \\ Universidade Estadual de Campinas - UNICAMP \\ Campinas, SP - Brasil \\ rfbeverari@gmail.com
}

\begin{abstract}
Resumo: Este artigo aborda a influência da cinematografia educativa internacional na formação do Instituto Nacional de Cinema Educativo (INCE). Reconhecido como primeiro órgão oficial voltado ao audiovisual em território nacional, o INCE funcionou de 1936 a 1966 no interior do Ministério da Educação e Saúde Pública com uma produção total de 407 obras entre curtas e médias metragens voltados à educação popular. Mediante uma pesquisa documental do Arquivo Gustavo Capanema, a pesquisa busca esboçar as aproximações e distanciamentos, nos primórdios deste órgão brasileiro, das experiências de cinema educativo na França, Itália, Alemanha e Estados Unidos em um período marcado por distintos projetos políticos do entreguerras.
\end{abstract}

Palavras-chave: ciências sociais; história; cinema; educação.

Abstract: This article approaches the influence of international educational cinematography in the formation of the National Institute of Educational Cinema. Recognized as the first official body dedicated to the audiovisual sector in Brazil, the INCE functioned from 1936 to 1966 within the Ministry of Education and Public Health, producing a total of 407 short and medium-length films aimed at popular education. Through a documental research of the then minister Gustavo Capanema, the research seeks to outline the approximations and distancements, in the beginning of this Brazilian agency, with the conception of educational cinema in France, Italy, Germany and the United States in a period marked by distinct political projects of the interwar period.

Keywords: social sciences; history; cinema; education.

\section{Para citar - ABNT NBR 6023:2018}

BEVERARI, Rafael Fermino. Transatlântico cinematográfico: aproximações e distanciamentos na formação do instituto nacional de cinema educativo. Cadernos de Pós-graduação, São Paulo, v. 20, n. 2, p. 63-75, jul./dez. 2021. Disponível em: https://doi.org/10.5585/cpg.v20n2.19683. 
Introdução

A impressão de realidade, fomentada pelas imagens em movimento, se popularizou com a disseminação dos cinematógrafos comercializados pelos irmãos Auguste e Louis Lumière. O desenvolvimento do cinema no início do século XX foi marcado por intensos debates, envolvendo sua utilização na sociedade, que perpassam por distintos interesses das classes proprietárias presentes em território brasileiro.

Nesse sentido, destacam-se os empenhos de Jonathas Serrano, Venâncio Filho e Joaquim Canuto Mendes. Enquanto os dois primeiros redigiram a obra "Cinema e Educação" em 1930, no ano seguinte, o último elaborou o livro intitulado "Cinema contra Cinema: bases geraes para um esboço de organisação do Cinema Educativo no Brasil". Essas referências buscaram problematizar os caminhos traçados pela cinematografia nacional ao discutirem os desafios de um cinema voltado ao seu aspecto educativo e formativo no conjunto da população brasileira.

Dessa maneira, Serrano e Venâncio Filho (1930, p. 92) apontam que "urge produzir, propagar, amparar por todas as formas o filme capaz de distrair sem causar damnos moraes, o filme de emoção sadia, não piégas, sem ridiculez, mas humano, patriotico, superiormente social.". Nesse sentido, Canuto Mendes (1931, p. 152) busca relacionar determinados princípios éticos com a produção, exibição e distribuição de uma obra audiovisual ao afirmar que "a educação enriquecerá os fins do cinema, dando-lhe o sentido moral da socialização do homem.".

Pois é na esteira desses acontecimentos que surge o Instituto Nacional de Cinema Educativo (INCE) em 1936. Pautado por um momento de incertezas acerca da consolidação de um ideário nacionalista e modernizante, este primeiro órgão, voltado especificamente à questão da organização cinematográfica, irrompe no cenário nacional. Por meio de uma pesquisa no Arquivo Gustavo Capanema - ministro que idealizou tal instituto - e no referido livro "Cinema e Educação", o presente artigo busca debater a influência estrangeira na consolidação do cinema educativo no Brasil. Dessa forma, a comunicação, em especial o cinema, se encontra como um importante instrumento de disseminação de ideias.

\section{O cinema e a busca pela unidade da nação}

O início do século XX brasileiro é marcado por transformações políticas no que tange as disputas do poder executivo, legislativo e judiciário. A busca pela construção de uma identidade nacional transcorre o cotidiano de uma sociedade pautada pelas contradições provenientes do seu próprio processo de desenvolvimento, de modo que a cisão entre campo e cidade vai além dos limites territoriais, representando um jogo pela conquista do poder econômico e político desse país. Diante deste contexto, "serão justamente a educação do povo, pela instrução pública, a reforma do 
ensino e a construção de um "campo cultural", a partir da universidade, que se tornarão os eixos de preocupação de uma boa parte da intelligentsia dos anos 20 e 30" (MARTINS, 1987, p. 75).

A principal via encontrada pela emergente força política proveniente do tenentismo, industriais e do meio artístico dos anos 1920 para enfrentar os problemas de seu tempo é por meio de um apelo ao nacionalismo (Cf. IANNI, 1971). Deste modo, não é de se estranhar a participação dos intelectuais na produção de ideais nacionalistas com a finalidade de unificar um país de tamanho continental como o Brasil. Neste momento de consolidação das forças em território nacional, a participação dos novos gestores também trilha esse mesmo caminho na construção de uma comunidade estruturada a partir de seus mitos de origem, língua, documentos antigos e demais eventos de um passado que reforça o sentimento de unidade.

Desta forma, é possível perceber a projeção de nação no Brasil do começo do século XX como uma comunidade imaginada; limitada internamente pela pretensa ideia de semelhanças nacionais e externamente pelas especificidades de cada povo; por fim, concebida como um espaço de soberania política. Afinal, "mais que inventadas, as nações são imaginadas, no sentido de que fazem sentido para a alma e constituem objetos de desejos e projeções" (ANDERSON, 2008, p. $10)$.

Levando em consideração tais ambições, ainda em 1928, o Decreto n. 3.281 de 23 de janeiro estabelece as diretrizes para a organização do ensino na capital federal, de modo que "todas as escolas de ensino primário, normal, doméstico e profissional, quando funcionarem em edifícios próprios, terão salas destinadas à instalação de projeção fixa e animada para fins meramente educativos" (SIMIS, 2015, p. 31). Dessa maneira, o desenho da construção de uma identidade nacional projetada pelas imagens em movimento por meio de espaços educativos começa a se rascunhar.

Até que em 1932, um grupo de 24 educadores redige o Manifesto dos pioneiros da Educação Nova. Esse documento se debruça sobre a centralidade de uma educação de qualidade na construção do que seria uma sociedade "livre e soberana". Dentre os pontos destacados, "a escola deve utilizar, em seu proveito, com a maior amplitude possível, todos os recursos formidáveis, como a imprensa, o disco, o cinema e o rádio..." (AZEVEDO et al., 2010, p. 62). Dentre os signatários, destaca-se a presença de Edgar Roquette-Pinto, do qual este artigo cruzará adiante.

A preocupação demonstrada no Manifesto mencionado sugere determinado grau de influência do campo audiovisual durante o regime varguista. O censo de 1933 fornecido pelo Instituto Nacional de Estatística - atual IBGE - aponta para a existência de 277 estabelecimentos de ensino, entre eles federal, estadual, municipal e particular que possuem o "aparelhamento 
especial para projeções luminosas animadas" ${ }^{1}$. Esse número sobe para 475 no ano seguinte. Uma vez que um dos pilares na credibilidade de um discurso é não deixar transparecer a construção que o sustenta, a questão que perpassa esse momento é sobre quais interesses tal demanda de exibição fílmica atende.

Em um país, cuja taxa de analfabetismo chega aos 65\% em 1920 e 56\% em 1940², a utilização das imagens possui uma função importante para a disseminação de informação. Atento a este fato, poucas cartelas de texto são colocadas no interior das primeiras obras audiovisual realizadas no Brasil. Com a sequência de projeção de imagens, sugestivas de acordo com a montagem elaborada, o público passa a vislumbrar diferentes aspectos de distintas regiões do Brasil.

Pois é em busca do controle deste meio de expressão que, em um discurso realizado em 1934, Getúlio Vargas (1938, p. 187) exalta o cinema como um dos "mais úteis fatores de instrução de que dispõe o Estado moderno". Deste modo, a cinematografia aproxima, "pela visão incisiva dos fatos, os diferentes núcleos humanos, dispersos no território vasto da República."(Id., 1983). Assim, como

elemento de cultura, influindo diretamente sôbre o raciocínio e a imaginação, êle apura as qualidades de observação, aumenta os cabedais científicos e divulga o conhecimento das coisas, sem exigir o esfôrço e as reservas de erudição que o livro requer e os mestres, nas suas aulas, reclamam (Id., p. 1983).

Ao aproximar o cinema, referenciado como "o livro de imagens luminosas", de um caráter educativo, ressalta ainda que é por meio deste espetáculo que "as nossas populações praieiras e rurais aprenderão a amar o Brasil, acrescendo a confiança nos destinos da Pátria. Para a massa de analfabetos, será essa a disciplina pedagógica mais perfeita, mais fácil e impressiva." (Ibid., p. 188). De tal forma, as "reservas" envolvendo a "erudição" de um livro são substituídas pela "fácil e impressiva" capacidade de percepção das imagens em movimento.

Logo, a latente preocupação com o material projetado é transposta, ainda antes de tal discurso, no Decreto n. 21.240 de $1932^{3}$, por meio de um processo de regulamentação das produções cinematográficos nacionais. Desse modo, "o filme documentário, seja de caráter científico, histórico, artístico, literário e industrial, representa, na atualidade, um instrumento de inigualável vantagem, para a instrução do público e propaganda do país, dentro e fora das fronteiras"4. Sobre o conteúdo audiovisual exibido, como "a exemplo dos demais países, e no

${ }^{1}$ Cf. http://biblioteca.ibge.gov.br/visualizacao/periodicos/20/aeb_1937.pdf Acessado em 10/11/2021.

${ }^{2}$ Cf. http://portal.inep.gov.br/documents/186968/485745/Mapa+do+analfabetismo+no+Brasil/a53ac9ee-c0c0-4727-b216035c65c45e1b?version=1.3>. Acessado em 10/11/2021

${ }^{3}$ Cf. https://www2.camara.leg.br/legin/fed/decret/1930-1939/decreto-21240-4-abril-1932-515832-publicacaooriginal-81522-pe.html. Acessado em 10/11/2021.

${ }^{4}$ Esta e as demais citações presentes até o fim do tópico são provenientes do Decreto n. 21.240 de 1932. 
interesse da educação popular, a censura dos filmes cinematográficos deve ter cunho acentuadamente cultural; e, no sentido da própria unidade da nação".

As novidades provenientes de diversos setores econômicos surgem como temas recorrentes na produção audiovisual dos anos 1930. Se o processo de industrialização é representado nas celulóides por meio do manejo das novas maquinarias, o Ministério da Agricultura também exibe seus feitos por meio da produção de filmes desde 1932. Cabe ressaltar o lugar que essas atividades econômicas ocupam nas telas e as intenções de seu uso a tal ponto de ser citada nominalmente em um decreto presidencial. Com a crescente burguesia industrial, a organização da força de trabalho irrompe como um assunto latente também no audiovisual brasileiro diante de um cenário de constantes transformações nos arranjos das forças produtivas.

Pois é neste cenário que o decreto de 1932 destaca que "serão considerados educativos, a juízo da comissão não só os filmes que tenham por objeto intencional divulgar conhecimentos científicos", mas também "aqueles cujo entrecho musical ou figurado se desenvolver em torno de motivos artísticos, tendentes a revelar ao público os grandes aspectos da natureza ou da cultura". Nestes moldes, qualquer temática de filme deveria passar pelo crivo do Ministério da Educação e Saúde Pública. A interdição das produções ficaria à critério deste órgão que deveria censurar a película que, entre outras situações, "ferir de qualquer forma a dignidade nacional ou contiver incitamentos contra a ordem pública, as forças armadas e o prestígio das autoridades e seus agentes". Assim, o governo Vargas, mesmo em sua fase inicial, oficializa a centralização das informações audiovisuais por meio dessa determinação que controla a produção e exibição pública nas escolas, cinemas e demais espaços culturais.

\section{As imagens luminosas}

Em 14 de novembro de 1930 foi criado o então Ministério dos Negócios da Educação e Saúde Pública. Após quatro anos de seu surgimento, Gustavo Capanema se torna ministro desta pasta. Em carta $^{5}$ enviada ao presidente Getúlio Vargas, em fevereiro de 1936, Capanema apresenta o projeto de lei, elaborado pelo "prof. Roquette Pinto", para regulamentação do Instituto Nacional de Cinema Educativo.

Com a ciência das dificuldades em implementar tal serviço público ainda no primeiro semestre do ano vigente, "pois para tanto seria necessario que se estabelecesse a sua organização", há um apelo para que o Instituto funcione, "se não como um serviço organizado (para o que se faz

${ }^{5}$ Este e os demais documentos citados neste artigo referentes à criação do Instituto Nacional de Cinema Educativo são encontradas em: Arquivo Gustavo Capanema, CPDOC/FGV, GCg 35.00.00/2. 
preciso decretar uma lei), pelo menos como um serviço em organização, o qual será, assim, um preparativo, um trabalho preliminar para o acto legislativo concernente à matéria.".

O artigo $1^{\circ}$ do "Projecto de Lei" elaborado por Roquette Pinto garante que o Instituto, ainda a ser criado, deveria ser "scientificamente autonomo" e subordinado ao Ministério da Educação. Este condicionamento do Instituto com o órgão responsável é também representado no artigo $5^{\circ}$, quando os "assumptos scientificos, artisticos e historicos" deveriam seguir as "instrucções" do "Ministro por proposta do director". Porém, quais são os caminhos planejados para a obtenção dessa pretensa neutralidade? Quais as influências do cinema educativo internacional na constituição do INCE?

Ainda sobre o Projeto de Lei, dentre os destaques do segundo artigo, concretiza-se a manutenção de uma filmoteca em sua sede localizada no Rio de Janeiro, a censura dos filmes educativos e a edição de material como aulas, conferências e palestras de professores. Além de tais tarefas, outros dois pontos propostos não foram executados durante os 30 anos do INCE. Um era a criação de uma revista voltada ao cinema educativo e a outra a realização de programas de "radiophonia" também destinados à tal temática.

Após anos de debate, que se inicia, oficialmente, em um decreto de 1932 acerca da necessidade de criação de um órgão sistematizador do cinema, o Instituto Nacional de Cinema Educativo finalmente é regulamentado em 1937 (em atividade desde 1936). Neste mesmo ano ocorre a criação do "Cine Jornal Brasileiro" (Cf. TOMAIM, 2006) - cinejornal oficial do Estado Novo, dirigido pelo Departamento Nacional de Propaganda, com existência até 1980.

Se, por um lado o Cine Jornal Brasileiro busca representar os últimos acontecimentos políticos e culturais do país voltados às imagens dos governantes, por outro, o INCE apresenta temas educativos das mais variadas formas com poucas aparições dos estadistas. Descobertas científicas, processo de alfabetização, culturas locais, fábulas, homenagens a artistas, processos de fabricação e organização das forças produtivas são algumas das temáticas exibidas em suas obras.

Porém, as discussões sobre a necessidade de centralização das informações se acirram ainda nas vésperas do Estado Novo. Apesar do INCE iniciar seu funcionamento em 1936, somente em 13 de janeiro de 1937 o Instituto é regulamentado pela Lei n. 378 que dita as competências do agora Ministério da Educação e Saúde, ocupado pelo ministro Gustavo Capanema. Dentre as disposições, o artigo 40 ressalta que "fica creado o Instituto Nacional de Cinema Educativo, destinado a promover e orientar a utilização da cinematographia, especialmente como processo auxiliar do ensino, e ainda como meio de educação popular em geral."6. As exibições eram realizadas em instituições culturais, escolas e antes de longas metragens nos cinemas.

6 Cf. < http://www2.camara.leg.br/legin/fed/lei/1930-1939/lei-378-13-janeiro-1937-398059-publicacaooriginal-1-pl.html>. Acessado em $10 / 11 / 2021$. 
Apesar de sua importância enquanto órgão regulamentador do cinema educativo em território nacional, as informações sobre disseminação do material produzido pelo instituto são escassas. Um registro aponta que até 1943, "havia 232 instituições cadastradas em todo o país, sendo 131 no Rio de Janeiro e 101 nos demais estados" (Ribeiro, 1944 apud Carvalhal, 2008, p. 60). O artigo $3^{\circ}$ do decreto n. 20.301 de $1946^{7}$ demonstra a preocupação em ajustar o discurso do material produzido com o governo de Vargas, uma vez que se estabelece que o diretor deve ter um secretário escolhido entre os funcionários do Ministério da Educação e Saúde. Ainda em relação ao conteúdo produzido, uma "Comissão Consultiva composta de cientistas e artistas de reconhecida autoridade" ${ }^{8}$, torna-se responsável pela aquisição de novas obras à filmoteca do INCE. O mesmo decreto garante a possibilidade do Instituto "documentar gratuitamente, na medida das suas possibilidades e a critério do diretor, as pesquisas científicas e técnicas originais, realizadas por pessoas idôneas"'.

O INCE perdura até 1966 e tem como seu entusiasta o médico, antropólogo e educador Edgard Roquette-Pinto, até então diretor do Museu Nacional que, mediante uma carta de Capanema de 12 de março de 1936, o convida a "organizar e dirigir o Instituto Nacional de Cinema Educativo"10. A indicação do professor recebeu o aval, um dia antes, do presidente Getúlio Vargas que o "considera muito boa escolha"11. Ele dirigiu o Instituto de 1936 a 1947, sendo responsável, em 28 de março de 1936, pela contratação de Humberto Mauro, técnico cinematográfico mineiro, que se dedicou na direção de 220 produções no instituto até 1964.

\section{Tour na Europa e a consolidação do cinema educativo no Brasil}

O desenvolvimento do cinema educativo pelo mundo ocorreu alguns anos após a disseminação do cinematógrafo pelos irmãos Lumière. Jonathas Serrano e Francisco Venâncio Filho (1930a, p. 137), ambos docentes do Colégio Pedro II e da Escola Normal do Rio de Janeiro, destacam que Itália, França, Alemanha e Estados Unidos "são os paízes mais poderosos e de cultura mais notavel que se interessam vivamente pelo problema" da produção, exibição e distribuição da crescente indústria audiovisual. Neste sentido, o livro intitulado "Cinema e Educação", publicado em 1930 pelos referidos professores, surge como um dos primeiros esforços de sistematização de uma cinematografia nacional conexa a um projeto pedagógico em território brasileiro. Sobre este assunto, afirmam (Ibidem, p. 66) que "a applicação do cinema ao ensino, deve-se condicionar aos

\footnotetext{
${ }^{7}$ Cf. https://www2.camara.leg.br/legin/fed/decret/1940-1949/decreto-20301-2-janeiro-1946-327734-publicacaooriginal-1-pe.html. Acessado em 10/11/2021.

${ }^{8}$ Decreto n. 20.301 de 1946

${ }^{9}$ Idem.

${ }^{10}$ Arquivo Gustavo Capanema, CPDOC/FGV, GCg 35.00.00/2.

${ }^{11}$ Idem.
} 
preceitos geraes da pedagogia", de modo que este não representaria um meio exclusivo de aprendizagem dissociado do ambiente escolar. O conteúdo fílmico também é um tema presente em suas discussões, uma vez que existiam filmes que educam e outros que deseducam, como por exemplo "a immensa maioria das comedias (como dos romances) [que] são idiotas ou prejudiciaes." (Ibidem, p. 91). Ao relatar questões técnicas referentes aos projetores, películas e até a disposição dos espaços de exibição, esta obra aponta para uma reflexão sobre os desdobramentos do cinema educativo no Brasil e no mundo.

$\mathrm{Na}$ esteira da consolidação cinematográfica internacional, em setembro de 1924, cerca de doze anos antes da criação do INCE, ocorre a fundação da L'Unione Cinematografica Educativa (LUCE), considerada por Roquette-Pinto como "a primeira organização de cinematographia educativa, realmente grandioza, que sob controle do Estado se apresenta ao mundo.". O idealizador e diretor deste órgão entre 1925 e 1928, professor Luciano De Feo, foi também um dos responsáveis pela criação do Instituto Internacional de Cinema Educativo (ICE), sob a tutela da Liga das Nações. Esta organização iniciou suas atividades em 1927, porém, com a iminência da $2^{a}$ Guerra Mundial, os conflitos se tornaram cada vez mais evidentes nos distintos países que compunham a Liga das Nações até a sua completa dissolução em 1937. Durante este período de funcionamento, evidencia-se os esforços para a organização da cinematografia educativa mundial em diversas ações que variam desde a realização de festivais até a publicação da Revista Internacional de Cinematografia Educativa. Este periódico, disseminado em cinco idiomas (italiano, francês, inglês, alemão e espanhol) circulou entre 1929 e 1934 com periodicidade mensal. A edição de outubro de 1930 publicou um texto intitulado "O cinema educativo no Rio de Janeiro" (SERRANO, 1930b, p. 1186, tradução nossa). Redigida pelo professor Jonathas Serrano - autor do livro, Cinema e Educação, já mencionado nesta pesquisa, a matéria aborda as iniciativas da capital federal na promoção do cinema educativo ao destacar os esforços de Fernando de Azevedo e a introdução da questão do audiovisual na reforma de ensino. Além disso, ressalta também uma exibição de cinematografia educacional, realizada em agosto de 1929, em uma escola no Rio de Janeiro. Considerada "a primeira deste tipo no Brasil e provavelmente a primeira em toda América do Sul" (Ibidem), este evento reuniu profissionais da educação de diversas localidades para debater os últimos acontecimentos da cinematografia educativa mundial. Segundo Serrano, destaca-se o auxílio da embaixada italiana ao enviar um projetor e alguns filmes produzidos pelo LUCE.

Alguns anos mais tarde, em fevereiro de 1937, ao buscar novas experiências acerca da produção, exibição e distribuição do cinema educativo, Edgard Roquette-Pinto parte para a Europa com a finalidade de elaborar um relatório com observações sobre tal projeto naquele continente. Em carta enviada ao ministro Capanema, o diretor do INCE aponta que: "cumprindo as instruções 
recebidas de V. Ex. procurei conhecer pessoalmente a organisação dos principaes institutos officiaes consagrados ao cinema educativo na Italia, na Allemanha e na França. ${ }^{12 " .}$

Como resultado de sua visita à Itália, o INCE foi convidado a participar do ICE "sem onus maior para o Brasil" e, como intercâmbio de material, deixou uma cópia do filme "Lição pratica de Taxidermia" (1936) à coleção do LUCE. Enquanto o cinema educativo brasileiro dava seus primeiros passos organizacionais, o órgão europeu possuía capital aberto com a presença das seguintes instituições: Commissariato Generale per L'Emigraz̧ione, Cassa Naz̧ionale per le Assicuraz̧ioni Sociali, Istituto Narionale delle Assicurazioni, Opera Nazionali Combattenti e Cassa Nazionale Assicurazioni Infortuni sul Lavoro. As particularidades do modo de gestão do governo italiano de Benito Mussolini frente ao contexto global não são citadas no documento. Assim, a discussão sobre os meandros do cinema educativo parece pairar diante de uma conjuntura formada pelas disputas do entreguerras.

$\mathrm{Na}$ Alemanha, o órgão responsável pelo agrupamento das diversas instituições pertencentes à indústria cinematográfica seria a Reichsfilmkammer, com existência desde 1923. Neste, o órgão central correspondente ao cinema educativo era o Reichstelle für den Unterrischtsfilm. Uma observação chama atenção ao elucidar que "a organização allemã separou o cinema educativo do cinema propaganda ou industrial. E nisto andou com acerto. Os interesses da educação publica exigem films da maior sinceridade; os da propaganda e os da arte... nem sempre.". A análise das produções perpassaria pelo controle do Ministério da Propaganda no Departamento Cultural "e tambem por orgãos do Partido Nazista (Gaupropagandaleiter der NSDAP).". Desta forma, o controle estatal de tal meio de comunicação parece se fundir com as propostas elaboradas por um partido que, em fevereiro de 1937, momento de tal expedição, já apresentava claros indícios de um autoritarismo que só iria se acentuar no decorrer dos acontecimentos. Novamente a pauta do cinema educativo, neste relatório, não tangencia as especificidades apresentadas pelas disputas políticas.

Dentre os países visitados, a França se destacaria com "a maior liberdade na exploração commercial de todos os typos de projecção animada.". O Musée Pedagogique aparece no documento como um dos espaços mais apropriados à produção, exibição e distribuição do audiovisual educativo, com um acervo de aproximadamente dez mil filmes.

Ainda neste relatório, alguns detalhes técnicos são debatidos em relação ao desenvolvimento do audiovisual em nível mundial. É o caso do cinema sonoro, visto diante de seu potencial "tanto para as pelliculas educativas como para as comuns destinadas ás pequenas salas proletarias ou particulares (Sociedades, Clubs, Fabricas, etc.).". Apesar da utilização de tal artefato ser visto com parcimônia pelos países europeus, Roquette-Pinto é categórico ao afirmar que "nós pensamos que, nas condições actuaes da technica, muito differentes das que dominavam em 1934,

${ }^{12}$ Esta e as demais citações presentes até o fim do tópico são encontradas no Arquivo Gustavo Capanema, CPDOC/FGV, GCg 35.00.00/2. 
desprezar o som, no cinema educativo, é abrir mão de 50\% das possibilidades do processo.". Além disso, destaca que "é certo que na França, na Italia e na Allemanha não existe, nem de longe, o enthusiasmo que os norte-americanos manifestam pelo film sonoro educativo de $16 \mathrm{~mm} . "$. A aproximação entre Brasil e Estados Unidos em relação a estas demandas específicas também ocorre quando, segundo Roquette-Pinto, na "questão das legendas (Didascalia) dos Italianos vamos procurando seguir antes os norte-americanos. Pensamos que o film educativo ideal fala por si mesmo; não precisa letreiros, que desviam a attenção.".

Uma crítica à indústria cinematográfica nacional irrompe em outro momento deste documento. A carência de película virgem no Brasil seria um dos motivos para a baixa qualidade do material produzido. Assim, Roquette-Pinto solicitou ao professor italiano e criador da LUCE, Luciano De Feo, e ao alemão Dr. Helmbrecht, "a indicação de technicos que pudessem ser contractados para o ensino da fabricação no Brasil, da pellicula virgem.".

Ainda, as observações realizadas durante esta viagem concluem que o INCE "não copiou servilmente nenhum dos grandes modelos do continente europeu.". Duas características fundamentais são levantadas acerca da produção do instituto brasileiro. Uma é a criação de "films educativos populares" - exibidos nas salas de cinema em todo território nacional - e a outra são os "films escolares" - com exibição nos institutos de ensino público e particular.

A influência da Alemanha nazista e da Itália fascista, comandadas respectivamente por Adolf Hitler e Benito Mussolini, na constituição da cinematografia brasileira se revela para além do conteúdo imagético. A separação entre o cinema educativo e o cinema de propaganda alemão pode ser observado, com certa semelhança em território nacional, diante do surgimento do Cine Jornal Brasileiro e Instituto Nacional de Cinema Educativo no mesmo ano com finalidades supostamente distintas. O forte controle estatal da estrutura do LUCE remete às tentativas, cada vez mais generalizantes, do controle do INCE frente ao conteúdo audiovisual oficial produzido em território nacional no tocante do cinema educativo. Deste modo, pensar a estrutura que possibilita a realização das obras no INCE é refletir sobre o conjunto organizacional do campo audiovisual nacional e sua relação no contexto global.

\section{Considerações finais}

O jogo de representação que permeia o imaginário social acerca da concepção de um projeto de nação é algo debatido antes mesmo da criação do INCE, onde é possível observar o importante papel do cinema no processo de reconhecimento dos "diferentes núcleos humanos" existentes no Brasil, de modo que, segundo Getúlio Vargas (1938, loc. cit.) 
o caucheiro amazônico, o pescador nordestino, o pastor dos vales do Jaguaribe ou do São Francisco, os senhores de engenho pernambucanos, os plantadores de cacau da Baía, seguirão de perto a existência dos fazendeiros de São Paulo e de Minas Gerais, dos criadores do Rio Grande do Sul, dos industriais dos centros urbanos; os sertanejos verão as metrópoles, onde se elabora o nosso progresso, e os citadinos, os campos e os planaltos do interior, onde se caldeia a nacionalidade do porvir.

O destaque dado à caracterização da população local por meio de uma ocupação profissional revela determinada apreensão do governo acerca das especificidades de cada região brasileira. Assim, como um processo fundamental de aproximação dos distintos rincões brasileiros, a necessidade de representação do território perpassaria o campo e a cidade composta por caucheiros, pescadores, pastores, senhores de engenho, fazendeiros e industriais. Segundo o presidente, as classes proprietárias e os trabalhadores encontram-se no mesmo nível de representatividade diante de uma "nacionalidade do porvir". Uma nação una, indivisível e harmoniosa do ponto de vista dos conflitos sociais é o desejo do poder executivo na produção cinematográfica elaborada nacionalmente, de modo que "o cinema, ao lado de sua função educativa, tomaria também outro papel fundamental para a política getulista: contribuir para unir e entrelaçar as forças vivas da nação." (SIMIS, 2015, p. 41).

Deste modo, a consolidação do INCE, em um momento marcado por distintas concepções de mundo, apontam para um embate sobre alguns aspectos envolvendo os interesses que permeiam a concretização do cinema educativo no Brasil, uma vez que

\begin{abstract}
ao sustentar que o cinema é natural, isto é, que ele representa a visão natural, é como afirmar que o real expressa-se sozinho na tela sem a interferência humana. Tal colocação implica, entre outros aspectos, na eliminação do grupo que produz a fala e consequentemente perde-se no horizonte que o cinema representa principalmente um ponto de vista. A história do cinema é em grande parte a luta constante para manter ocultos os aspectos artificiais do cinema e para sustentar a impressão de realidade. $\mathrm{O}$ cinema, como toda área social, é um campo de luta e a história do cinema é também o esforço constante para denunciar esse ocultamento e fazer aparecer quem fala. (BERNARDET, 1980, p. 11).
\end{abstract}

Ao levar em consideração as particularidades da consolidação do cinema educativo no Brasil em um momento de consolidação do Estado Novo - e com isto todo um ideário nacional -, a visita de Edgard Roquette-Pinto na Alemanha, França e Itália demonstra aproximações e distanciamentos destes países, bem como a influência direta do setor cinematográfico estadunidense no tocante de questões técnicas sobre a produção audiovisual. Conforme relatado neste artigo, cabe salientar que a estruturação do campo cinematográfico em território nacional não se concretiza sem levar em consideração as experiências dos demais países do mundo. Curioso destacar que, levando em consideração os documentos oficiais do Ministério da Educação e Saúde, 
mesmo em um período repleto de conflitos mundiais, as considerações acerca da produção fílmica educativa não polemizam quanto às políticas internacionais adotadas pelas distintas nações.

Deste modo, refletir sobre os primórdios da organização do cinema educativo no Brasil é se adentrar em um emaranhado de relações internacionais composto por uma série descontínua de posições. Sem desconsiderar as particularidades provenientes da formação da nação brasileira presentes em tal órgão, é importante destacar as influências de países com distintos projetos políticos em um momento pautado pelo entreguerras. Neste período, mediante adesões ora de um lado, ora de outro, o Instituto Nacional de Cinema Educativo estabeleceu suas bases para a consolidação deste setor da cinematografia em território brasileiro.

\section{Referências}

ALMEIDA, Joaquim Canuto Mendes de. Cinema Contra Cinema. São Paulo: Editora Limitada, 1931.

ANDERSON, Benedict. Comunidades Imaginadas - reflexões sobre a origem e a difusão do nacionalismo. São Paulo: Cia das Letras, 2008.

AZEVEDO et al. Manifestos dos pioneiros da Educação Nova. Recife: Massangana, 2010.

BERNARDET, Jean-Claude. O que é cinema. São Paulo: Brasiliense, 1980

BRASIL. Decreto n²1.240, de 4 de abril de 1932 in Diário Oficial da União - Seção 1 - 15 de abril de 1932, p. 7146, 1932.

BRASIL. Lei n 378, de 13 de janeiro de 1937 in Diário Oficial da União - Seção 1 - 15 de janeiro de 1937, p. 1210, 1937.

BRASIL. Decreto n 20301, de 2 de janeiro de 1946 in Diário Oficial da União - Seção 1 - 10 de janeiro de 1946, p. 403, 1946.

CARVALHAL, Fernanda Caraline de Almeida. Luæ, câmera, educação! - O Instituto Nacional de Cinema Educativo e a formação da cultura áudio-imagética escolar. Dissertação (Mestrado) Universidade Estácio de Sá, Rio de Janeiro, 2008.

GOMES, Angela de Castro. A invenção do trabalbismo. Rio de Janeiro: Editora FGV, 2005.

IANNI, Octávio. Estado e planejamento econômico no Brasil. São Paulo: Civilização Brasileira, 1971.

LESSA, Renato. A invenção republicana: Campos Sales, as bases e a decadência da Primeira República brasileira. Rio de Janeiro:Topbooks, 2015.

MARTINS, Luciano. A gênese de uma intelligentsia; os intelectuais e a politica no Brasil, 1920-1940. São Paulo: Revista Brasileira de Ciências Sociais, v. 2, n. 4, 1987. 
ROQUETTE-PINTO, Edgard. Notas Sobre os tipos antropológicos do Brasil. In: Actas e Trabalhos do I Congresso Brasileiro de Eugenia, Rio de Janeiro, vol. I, 1929.

SERRANO, Jonathas e VENÂNCIO FILHO, Francisco. Cinema e Educação. São Paulo, Cayeiras, Rio: Melhoramentos, vol. XIV, 1930a.

SERRANO, Jonathas. The educational cinema at Rio de Janeiro. International Review of Educational Cinematography, p.1186-1188, out 1930b, n. 10.

SIMIS, Anita. Estado e cinema no Brasil. São Paulo: Editora Unesp, 2015.

SOUZA, Carlos Roberto de. Catálogo filmes produridos pelo INCE. Rio de Janeiro: Fundação do Cinema Brasileiro, 1990.

TOMAIM, Cássio dos Santos. Janela da Alma: Cinejornal e Estado Novo -fragmentos de um discurso totalitário, São Paulo: Annablume, 2006.

VARGAS, Getúlio. O cinema nacional, elemento de aproximação dos habitantes do País. In: $A$ nova política do Brasil. Rio de Janeiro : José Olympio, 1938.

\section{Coleções pessoais}

Gustavo Capanema (CPDOC/FGV). 